\title{
INTERFACING
}

Something of a shibboleth, interface. Many people contentedly interface while they keyboard, inputting and outputting as they go; others detest the word as the ugliest of neologisms, a word that demonstrates the tragic ease with which any noun in English can be verbed (for more on this, see Whitney Bolton on p. 39).

Whatever interface is, however, it is not new. The $O E D$ has an 1880 citation for it, as 'a surface lying between two portions of matter or space, and forming their common boundary'. It is only a short step from that to current computer use. And interfacing - the verbal use - has been strong in the garment industry for decades. A little etymological research is often useful (and for more of that, see p. 26).

An awareness of etymology, however, does not always tip the scales of linguistic love and hate - a point that is particularly true of 'strong', 'foul', 'profane' or 'taboo' language. That is an area where fashions change and hackles easily rise - and Shirley Peckham opens that debate with David Crystal on p. 34.

Interfacing occurs where systems meet. If there is anything central to the brief of this magazine it is the description and discussion of what happens when language systems meet - whether they are the systems of distinct languages, or special varieties inside the ambit of 'World English'. In the seven issues of ET to date we have looked at many other languages, and in this issue the interlingual discussion goes on, this time shifting into the area of bilingualism. Brita Haycraft, Jean-Paul de Chezet and Edith Harding offer several slants on what goes on inside bilingual heads and households (pp. 27-33).

As regards the varieties of English itself, past issues have ranged from Scotland to the Caribbean and Texas to India. This time, it is the turn of black Africa (pp. 13-16), while the cover theme itself explores the usage industry, whose roots go back at least to 1600 . The nature of the 'standard' language, the question of 'good' versus 'bad' usage - these are perennially prickly topics, and letters to the editor demonstrate that readers want them aired. Making usage the July cover theme was not originally part of our plan for 1986 - and has put back our consumer report on dictionaries to January 87 - but the cause is a good one: How else to deal with the umpteen usage books (revisions of old stalwarts or entirely new works) that have been flooding in for review? The tradition of the bibles of usage is alive and well and living in many publishers' lists.

In addition to which, there is also room in ET7 for the romance of English in China (p. 4), the centennial of Jekyll and Hyde (p. 7), and the putative origins of the English language among the Tuluas of south India (p. 5). We have an interview with $L$ G Alexander that should interest all practising language teachers, while literature enthusiasts will find the diverse elements of the diaspora of English literature drawn together by Douglas Killam. In the reviews I look again at English's linguicidal reputation, while Maggie Cook writes about books of children's poetry that are not only good in themselves but give their royalties to the Save the Children's Fund (p. 41). As they say in Ashkenazic English - Enjoy!

Tom McArthur

The editorial policy of English Today is to provide a focus or forum for all sorts of news and opinion from around the world. The points of view of individual writers are as a consequence their own and do not reflect the opinion of the editorial board. In addition, wherever feasible, ET leaves unchanged the orthography (normally British or American) and the usage of individual contributors, although the editorial style of the magazine itself is that of Cambridge University Press.

\section{A Call for Papers}

In $E T$ 's files we have cuttings/clippings from a wide range of British and North American newspapers, and a scattering of material from many other sources. If readers would care to add to our files by sending in occasional (titled and dated) material from their local newspapers, etc., or even the odd complete sample of a specially interesting periodical, this would be a great help in widening the range of usage which we can quote in From Our Files.

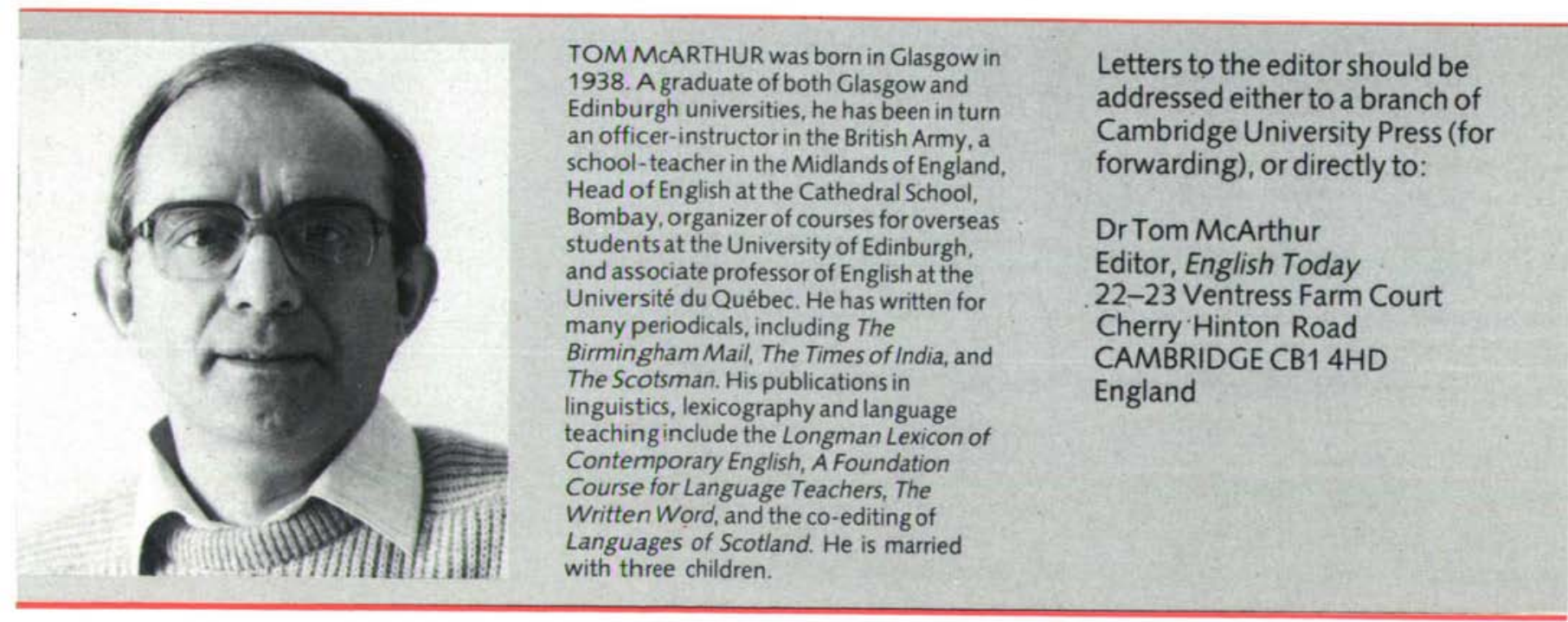

